\title{
The albumin to globulin ratio is associated with mucosal healing in Japanese patients with ulcerative colitis: A cross-sectional study
}

\section{Sen Yagi}

Saiseikai Matsuyama Hospital

Shinya Furukawa ( $\square$ shinya.furukawa@gmail.com )

Ehime University

Kana Shiraishi

Ehime University

Masakazu Hanayama

Ehime University

Kazuhiro Tange

Ehime University

Yu Hashimoto

Ehime University

\section{Shogo Kitahata}

Ehime University

Kenichirou Mori

Ehime Prefectural Central Hospital

Tomoyuki Ninomiya

Ehime Prefectural Central Hospital

\section{Seiyuu Suzuki}

Sumitomo Besshi Hospital

Naozumi Shibata

Ehime prefectural Niihama Hospital

Hidehiro Murakami

Saiseikai Matsuyama Hospital

Katsuhisa Ohashi

Ohashi Clinic

Makoto Yano

Yano Clinic

Aki Hasebe

Shikoku Cancer Center

Hideomi Tomida 
Ehime University

Yasunori Yamamoto

Ehime University

\section{Eiji Takeshita}

Ehime University

\section{Yoshio Ikeda}

Ehime University

\section{Yoichi Hiasa}

Ehime University

\section{Research Article}

Keywords: albumin to globulin ratio, mucosal healing, ulcerative colitis

Posted Date: January 16th, 2021

DOl: https://doi.org/10.21203/rs.3.rs-144470/v1

License: (c) (i) This work is licensed under a Creative Commons Attribution 4.0 International License. Read Full License 


\section{Abstract \\ Background}

Ulcerative colitis (UC) is a chronic inflammatory disease. Mucosal healing (MH) is inversely associated with clinical outcome. The albumin to globulin ratio (AGR) is known as chronic inflammation marker. While some evidence regarding an association between AGR and some chronic diseases has been reported, no evidence regarding association between AGR and UC exists. The aim of this study to evaluated the association between AGR and MH among Japanese patients with UC.

\section{Methods}

The study subjects consisted of 273 Japanese patients with UC. AGR was divided into quartiles on the basis of the distribution of all study subjects. One endoscopic specialist was responsible for evaluating $\mathrm{MH}$, which was defined as a Mayo endoscopic subscore of 0 or $0-1$. Age, sex, steroid use, body mass index, age at onset of UC, and anti-TNFa preparation were selected a priori as potential confounding factors.

\section{Results}

The mean age was 51.2 years, and the percentage of male patients was $59.0 \%$. The percentage of $\mathrm{MH}$ was $26.4 \%$. High AGR $(1.483<$ AGR $\leq 1.643)$ and very high AGR $(>1.643)$ was significantly positively associated with MH (OR 2.21 [95\% Cl: 1.12-4.47], p for trend $=0.001)$ after adjustment for confounding factors. No association between AGR and partial MH was found. The independent positive association between $\mathrm{AGR}$ and $\mathrm{MH}$ was found in only low $\mathrm{C}$-reactive protein group.

\section{Conclusion}

Among Japanese patients with UC, AGR was significantly positively associated with $\mathrm{MH}$, was significantly positively associated with $\mathrm{MH}$ especially in the low $\mathrm{C}$-reactive protein group.

\section{Background}

Ulcerative colitis (UC) is a chronic inflammatory bowel disease (IBD) characterized by a disease course involving relapses and remissions [1]. Mucosal healing $(\mathrm{MH})$ is inversely associated with clinical relapse, rates of hospitalization and surgery, and incidence of colorectal cancer [2-7]. Thus, MH has been indicated as the therapeutic goal for UC.

The prospective studies have shown that strict control based on monitoring of inflammatory biomarkers and maintenance of $\mathrm{MH}$ [8]. The concept of the treat-to-target in UC had accepted to improve the 
prognosis. The implications of $\mathrm{MH}$ had led to improved endoscopic and clinical outcomes. Colonoscopy findings are essential for assessing $\mathrm{MH}$ and Fecal calprotectin $(\mathrm{FC})$ is most reliable marker for $\mathrm{MH}$. However, repeated endoscopy and stool examination are extremely burdensome for patients. repeated fecal examinations may be distressing for women, the young, or patients without symptoms. More serum markers for $\mathrm{MH}$ that can be measured repeatedly, easily, and rapidly is needed for achieve the concept of the treat-to-target among ulcerative colitis.

Albumin and globulin are the two major components of serum proteins. The albumin to globulin ratio (AGR), calculated as serum albumin/ (total protein - albumin), has been used one of marker for chronic inflammation. AGR has been reported to be a prognostic marker in patients with cancers [9-15], chronic heart failure [16], stroke [17], and sarcoidosis [18]. However, no evidence regarding association between AGR and clinical outcomes among patients with UC exits. Thus, we aimed to evaluate the association between AGR and MH among Japanese patients with UC.

\section{Materials And Methods}

\section{Study population}

The study subjects consisted of 387 Japanese patients with UC at the Department of Gastroenterology and Metabology at the Ehime University Graduate School of Medicine, and at several affiliated hospitals in Ehime prefecture (The Ehime Clinical Network for Alimentary Diseases study group). All patients were diagnosed with UC according to endoscopic, radiological, histological, and clinical criteria. After 114 patients were excluded due to incomplete data, the final analysis sample in this study consisted of 273 patients assessed for endoscopy examination, medication, serum albumin, and serum globulin. The study protocol conforms to the ethical guidelines of the 1975 Declaration of Helsinki (6th revision, 2008). This protocol was approved by the Institutional Review Board of the Ehime University Graduate School of Medicine (1505011). Well trained staff obtained written informed consent from all patients enrolled.

\section{Measurements}

Information on endoscopic findings, age at onset of UC, use of drugs for UC, C-reactive protein (CRP), AGR was collected using medical records and self-. Serum albumin, globulin and CRP were determined from routine blood levels obtained from patient files at the time the patients were included in the study. Blood samples were taken the morning after overnight fasting. Blood examination was collected when a colonoscopy is reserved or when the colonoscopy examination is performed. There could be a time difference of about two months. Height was measured to the nearest millimeter using a stadiometer with the patients standing completely erect. Weight was measured in light clothing. BMI was calculated as weight in kilograms divided by square height in meters.

\section{Definition of mucosal healing}

We evaluated mucosal status by total colonoscopy. The Mayo endoscopic score (MES) consists of the following four categories [19]: 0 , normal or inactive disease; 1 , mild disease with erythema, decreased 
vascular patterns, and mild friability; 2, moderate disease with marked erythema, absence of vascular patterns, friability, and erosions; 3 , severe disease with spontaneous bleeding and ulceration. $\mathrm{MH}$ and partial $\mathrm{MH}$ were defined as category 0 and $0-1$, respectively, in this study. One endoscopic specialist was responsible for evaluating MES and $\mathrm{MH}$, and was blinded to AGR.

\section{Statistical analysis}

AGR was divided into quartiles on the basis of the distribution of all study subjects. AGR level was classified into four categories: 1) low AGR, < 1.281 (reference); 2) moderate AGR, 1.281-1.483; 3) high AGR, 1.483-1.643; and 4) very high $A G R,>1.643$. Estimations of crude odds ratios (ORs) and their $95 \%$ confidence intervals (Cls) for $\mathrm{MH}$ and partial $\mathrm{MH}$ in relation to AGR were performed using logistic regression analysis. Multiple logistic regression analyses were used to adjust for potential confounding factors. Age, sex, steroid use, BMI, onset age, and anti-TNFa preparation were selected a priori as potential confounding factors. A receiver operating characteristic (ROC) curve was generated, and the area under the curve was calculated to indicate the utility of the AGR for mucosal healing. We used Youden Index to calculate the cut off value of platelet. Statistical analyses mainly were performed using SAS software package version 9.4 (SAS Institute Inc., Cary, NC, USA). ROC curve, cut off value of AGR, sensitivity and specificity were analyzed using JMP 14.2 (SAS Institute Inc., Cary, NC, USA). All probability values for statistical tests were two-tailed, and $\mathrm{P}<0.05$ was considered statistically significant.

\section{Results}

Table 1 shows the characteristics of the 273 study participants. The mean age was 51.2 years, and the percentage of male patients was $59.0 \%$. Use of 5 -aminoasalicylates, prednisolone, and TNF-a monoclonal antibody preparations were reported at $90.8 \%, 21.3 \%$, and $5.9 \%$, respectively. The percentage of MH was $26.4 \%$, and the mean AGR was $1.461 \pm 0.291$. In this cohort, median CRP was $0.099 \mathrm{mg} / \mathrm{dl}$. The ROC curve of AGR for identifying the mucosal healing had an area under curve of 0.613 (Fig. 1) 
Table 1

Clinical characteristics of 273 study participant

\begin{tabular}{ll|}
\hline Variable & $\mathbf{n}(\%)$ \\
\hline Age, years, mean \pm SD & $51.2 \pm 16.2$ \\
\hline Male (\%) & $161(59.0)$ \\
\hline Disease extent (pancolitis/left-sided/proctitis/others) & $114 / 74 / 78 / 7$ \\
\hline Age at onset of UC, age, mean \pm SD & $42.4 \pm 16.3$ \\
\hline BMl, mean \pm SD & $22.69 \pm 4.60$ \\
\hline Medication & \\
\hline 5-aminosalicylates (\%) & $248(90.8)$ \\
\hline Prednisolone (\%) & $58(21.3)$ \\
\hline TNF- $a$ monoclonal antibody (\%) & $16(5.9)$ \\
\hline Clinical remission, (\%) & $157(57.5)$ \\
\hline Mayo endoscopic subscore, mean \pm SD & $1.18 \pm 0.91$ \\
\hline Mucosal healing (Mayo endoscopic subscore<1) (\%) & $72(26.4)$ \\
\hline Partial mucosal healing (Mayo endoscopic subscore $\leq 1)(\%)$ & $172(63.0)$ \\
\hline AGR, mean \pm SD & $1.461 \pm 0.291$ \\
\hline CRP, mg/dl, median \pm IQR & $0.099 \pm 0.23$ \\
\hline $\begin{array}{l}\text { BMl, body mass index; SD, standard deviation; TNF, tumor necrosis factor; AGR, albumin globulin } \\
\text { ratio; CRP, C-reactive protein; IQR, inter-quartile range }\end{array}$ \\
\hline
\end{tabular}

Table 2 shows crude and adjusted ORs and $95 \% \mathrm{Cls}$ for $\mathrm{MH}$ and partial MH in relation to AGR. Very high AGR was positively associated with $\mathrm{MH}$ and partial $\mathrm{MH}$ (MH: crude OR 3.52 [95\% Cl: 1.53-8.69] and partial MH: crude OR 2.07 [95\% Cl: 1.02-4.25]). High AGR was positively associated with MH but not partial MH (crude OR 3.52 [95\% Cl: 1.53-8.69]). After adjustment for age, sex, steroid use, body mass index, age at onset of UC, and anti-TNFa preparation, very high AGR and high AGR were significantly positively associated with $\mathrm{MH}$, respectively (adjusted OR 5.57 [95\% Cl: 2.12-15.80] and adjusted OR 4.22 [95\% Cl: $1.65-11.63]$, p for trend $=0.001$ ). The positive association between AGR and partial MH disappeared after adjustment for these confounding factors. 
Table 2

Crude and adjusted odds ratios and 95\% confidence intervals for $\mathrm{MH}$ and partial $\mathrm{MH}$ relation to AGR

\begin{tabular}{|c|c|c|c|}
\hline Variable & Prevalence (\%) & $\begin{array}{l}\text { Crude OR } \\
(95 \% \mathrm{Cl})\end{array}$ & $\begin{array}{l}\text { Adjusted OR } \\
(95 \% \mathrm{Cl})\end{array}$ \\
\hline \multicolumn{4}{|l|}{$\mathrm{MH}$} \\
\hline$A G R \leq 1.281$ & 9/67 (13.4) & 1.00 & 1.00 \\
\hline $1.281<\mathrm{AGR} \leq 1.483$ & $16 / 70(22.9)$ & $1.91(0.79-4.85)$ & $2.40(0.93-6.53)$ \\
\hline $1.483<$ AGR $\leq 1.643$ & 23/68 (33.8) & $3.29(1.43-8.16)$ & $4.22(1.65-11.63)$ \\
\hline $1.643<$ AGR & 24/68 (35.3) & $3.52(1.53-8.69)$ & $5.57(2.12-15.80)$ \\
\hline$P$ for trend & & & 0.001 \\
\hline \multicolumn{4}{|l|}{ Partial MH } \\
\hline$A G R \leq 1.281$ & $36 / 67$ (53.7) & 1.00 & 1.00 \\
\hline $1.281<\mathrm{AGR} \leq 1.483$ & $41 / 70(58.6)$ & $1.22(0.62-2.40)$ & $1.09(0.52-2.28)$ \\
\hline $1.483<\mathrm{AGR} \leq 1.643$ & 47/68 (69.1) & $1.93(0.96-3.93)$ & $1.59(0.72-3.54)$ \\
\hline $1.643<$ AGR & 48/68 (70.6) & $2.07(1.02-4.25)$ & $1.84(0.82-4.19)$ \\
\hline$P$ for trend & & & 0.096 \\
\hline \multicolumn{4}{|c|}{$\begin{array}{l}\text { Adjusted for age, sex, use of prednisolone, BMl, onset age, and use of TNF-a. OR, odds ratio; } \mathrm{Cl} \text {, } \\
\text { confidence interval; } \mathrm{MH} \text {, mucosal healing; AGR, albumin to globulin ratio }\end{array}$} \\
\hline
\end{tabular}

The association between AGR and MH after CRP stratification was shown in Table 3. In low CRP group ( $\leq 0.1 \mathrm{mg} / \mathrm{dL}$ ), AGR was significantly positively associated with $\mathrm{MH}$ but not partial MH (very high: adjusted OR 4.48[95\% Cl: 1.09-22.19], p for trend $=0.014)$. In high CRP group (CRP $>0.1 \mathrm{mg} / \mathrm{dL})$, no association between AGR and MH found. 
Table 3

Crude and adjusted odds ratios and $95 \%$ confidence intervals for mucosal healing in relation to AGR after CRP stratification

\begin{tabular}{|c|c|c|c|}
\hline Variable & Prevalence (\%) & $\begin{array}{l}\text { Crude OR } \\
(95 \% \mathrm{Cl})\end{array}$ & $\begin{array}{l}\text { Adjusted OR } \\
(95 \% \mathrm{Cl})\end{array}$ \\
\hline \multicolumn{4}{|l|}{$\begin{array}{l}C R P \leq 0.1 \mathrm{mg} / \mathrm{dL} \\
(\mathrm{n}=158)\end{array}$} \\
\hline \multicolumn{4}{|l|}{ MH (MES 0) } \\
\hline$A G R \leq 1.281$ & $4 / 19(21.1)$ & 1.00 & 1.00 \\
\hline $1.281<$ AGR $\leq 1.483$ & $10 / 44(22.7)$ & $1.10(0.31-4.53)$ & $1.59(0.39-7.55)$ \\
\hline $1.483<$ AGR $\leq 1.643$ & 16/41 (39.0) & $2.40(0.72-9.59)$ & $3.54(0.87-17.08)$ \\
\hline $1.643<A G R$ & 20/54 (37.0) & $2.21(0.69-8.56)$ & $4.48(1.09-22.19)$ \\
\hline$p$ for trend & & & 0.014 \\
\hline \multicolumn{4}{|l|}{ Partial MH (MES 0-1) } \\
\hline $\mathrm{AGR} \leq 1.281$ & 15/19 (79.0) & 1.00 & 1.00 \\
\hline $1.281<$ AGR $\leq 1.483$ & 27/44 (61.4) & $0.42(0.11-1.40)$ & $0.41(0.10-1.49)$ \\
\hline $1.483<\mathrm{AGR} \leq 1.643$ & $31 / 41(75.6)$ & $0.83(0.20-2.94)$ & $0.67(0.14-2.71)$ \\
\hline $1.643<$ AGR & $39 / 54(72.2)$ & $0.69(0.18-2.28)$ & $0.60(0.13-2.34)$ \\
\hline$p$ for trend & & & 1.00 \\
\hline \multicolumn{4}{|l|}{$\begin{array}{l}C R P>0.1 \mathrm{mg} / \mathrm{dL} \\
(\mathrm{n}=115)\end{array}$} \\
\hline \multicolumn{4}{|l|}{ MH (MES 0) } \\
\hline$A G R \leq 1.281$ & 5/48 (10.4) & 1.00 & 1.00 \\
\hline $1.281<$ AGR $\leq 1.483$ & $6 / 26(23.1)$ & $2.58(0.70-9.94)$ & $2.34(0.58-9.73)$ \\
\hline $1.483<$ AGR $\leq 1.643$ & $7 / 27(25.9)$ & $3.01(0.86-11.31)$ & $3.28(0.81-14.75)$ \\
\hline $1.643<$ AGR & 4/14 (28.6) & $3.44(0.74-15.46)$ & $3.35(0.63-18.30)$ \\
\hline$p$ for trend & & & 0.09 \\
\hline Partial MH (MES 0-1) & & & \\
\hline
\end{tabular}

Adjusted for age, sex, use of prednisolone, BMI, onset age, and use of TNF-a.

OR, odds ratio; $\mathrm{Cl}$, confidence interval; AGR, albumin to globulin ratio; CRP, C-reactive protein 


\begin{tabular}{|llll|}
\hline Variable & Prevalence $(\%)$ & $\begin{array}{l}\text { Crude OR } \\
(95 \% \mathrm{Cl})\end{array}$ & $\begin{array}{l}\text { Adjusted OR } \\
(95 \% \mathrm{Cl})\end{array}$ \\
\hline AGR $\leq 1.281$ & $21 / 48(43.8)$ & 1.00 & 1.00 \\
\hline $1.281<\mathrm{AGR} \leq 1.483$ & $14 / 26(53.9)$ & $1.50(0.58-3.97)$ & $1.04(0.35-3.07)$ \\
\hline $1.483<$ AGR $\leq 1.643$ & $16 / 27(59.3)$ & $1.87(0.73-4.97)$ & $1.47(0.48-4.60)$ \\
\hline $1.643<$ AGR & $9 / 14(64.3)$ & $2.31(0.69-8.51)$ & $1.93(0.46-9.08)$ \\
\hline$p$ for trend & & & 0.33 \\
\hline Adjusted for age, sex, use of prednisolone, BMl, onset age, and use of TNF-a.
\end{tabular}

\section{Discussion}

In the present study, AGR was independently positively associated with $\mathrm{MH}$ among 273 Japanese patients with UC, and ours is the first such study to show a significant positive association between AGR and $\mathrm{MH}$ among patients with UC. AGR is independently positively associated with $\mathrm{MH}$ but not partial $\mathrm{MH}$ among patients with only low CRP UC.

Albumin and globulin are the two major components of serum proteins, and their levels correlate with systemic inflammation [11-13]. Albumin maintains osmotic pressure and functions [20]. Low serum albumin is associated with not only nutritional status but also chronic inflammation [13,21]. Low serum albumin could weaken the human immune system, thus increasing susceptibility to infection and resulting in cytokine-induced suppression [22,23]. On the other hand, globulin consists of all types of proinflammatory proteins. A high level of globulin indicated a systematic inflammatory response [24]. Serum globulin level is thought to reflect the degree of continuous systemic inflammation. AGR is less sensitive and less susceptible to measurement variability such as dehydration or fluid retention since it is a ratio rather than an absolute value [9].

AGR has been reported to be a prognostic marker in patients with colorectal [8], lung [10], and breast cancers [11]. Furthermore, AGR is an independent predictor of mortality in patients with chronic heart failure [16]. AGR is significantly inversely associated with cardiovascular diseases and incidence of stroke $[17,25]$. Additionally, an inverse association between AGR and the clinical activity was reported among patients with sarcoidosis [18]. The findings in the present study consistent with these findings regarding the AGR and clinical outcomes.

Colonoscopy findings are essential for assessing mucosal status in patients with UC and determining treatment strategies. FC is useful and reliable marker for $\mathrm{MH}$. However, repeated endoscopy is extremely burdensome for patients. Similarly, repeated fecal examinations may be distressing for the young, women, or patients without symptoms. Additionally, colonoscopy and FC might be not suitable for 
assessment for early response for medication. AGR is simple, rapid, relatively non-invasive, repeatable, and can be measured at all medical institutions. AGR monitoring might be useful to assessment disease activity, treatment response, and prognosis especially among UC patients with low CRP level. However, further research is needed for assessment AGR as a biomarker for diseases activity among patients with UC.

The underlying mechanism linking AGR and $\mathrm{MH}$ remains unclear, but there are several biologically plausible options. Serum albumin is known to decrease during inflammation [26]. In fact, in 43 patients with UC, CRP was significantly inversely associated with serum albumin [27]. Because of intestinal tract inflammation, protein loss from the gut and malnutrition may influence serum albumin levels [28]. AGR was associated with plasma TNF-a levels in community-dwelling Japanese elderly women [29]. Levels of a1 globulins (a1-antitrypsin, thyroid-binding globulin, and transcortin) and a2 globulins (ceruloplasmin, a2-macroglobulin, and haptoglobin) are also increased in acute inflammation [30]. Intestinal tract inflammation might elevate AGR with protein loss and elevated TNF-a.

This study has several limitations. First, this was a cross-sectional analysis; therefore, we cannot conclude that there is a causal association between AGR and MH. Second, in this cohort, the sample size was small. Third, the exclusion rate was high. Fourth, we could not estimate the dietary intake of protein. Fifth, most of the patients have been receiving treatment for UC. The long duration of medication might therefore might affect AGR value. Finally, the current study patients might be an unrepresentative sample of Japanese patients with UC. The use of medication in Japanese study based on claims data were similar to those in the present study [31]. However, since this cohort consist of Japanese patients, the findings in the present study might not be generalized to other cohorts.

\section{Conclusions}

Among Japanese patients with UC, AGR may be independently positively associated with MH was significantly positively associated with $\mathrm{MH}$ especially in the low C-reactive protein group.

\section{Abbreviations}

AGR: albumin to globulin ratio; MH: mucosal healing; UC: ulcerative colitis; FC: Fecal calprotectin; TNF: tumor necrosis factor; IBD: inflammatory bowel disease; CRP: C-reactive protein; MES: Mayo endoscopic subscore; ROC: receiver operating characteristic

\section{Declarations}

\section{Ethics approval and consent to participate}

The study protocol was approved by the institutional review board of the Ehime University Graduate School of Medicine (1505011). Well-trained staff obtained written informed consent from all patients enrolled. 


\section{Consent for publication}

Not applicable.

\section{Availability of data and materials}

The datasets used and/or analyzed during the current study are available from the corresponding author on reasonable request.

\section{Funding}

Not applicable.

\section{Competing interests}

Not applicable

\section{Authors' contribution}

Conception and design: SY, FS, ET, YI, YH; Material preparation and data collection: SY, SF, KS, MH, KT, SK, $\mathrm{KM}, \mathrm{TN}, \mathrm{SS}, \mathrm{NS}, \mathrm{HM}, \mathrm{KO}, \mathrm{MY}, \mathrm{AH}, \mathrm{HT}, \mathrm{YY}, \mathrm{ET}$, Yl; Data analysis: SF; Interpretation of data: SY, SF, ET, YI, and $\mathrm{YH}$; The first draft of the manuscript was written by SY and SF; Supervision: YH. All authors read and approved the final manuscript.

\section{Acknowledgements}

The authors would like to thank Keitarou Kawasaki, Yuji Mizukami, Masayoshi Uraoka, Sanae Nakamura, Satoshi Nakamura, Masamoto Torisu, Makoto Yano, Harumi Yano, Masato Murakami, Hino Harumi, Tomo Kogama and the ECNAD study group for their support.

\section{References}

1. Langholz E, Munkholm P, Davidsen M, Binder V. Course of ulcerative colitis: analysis of changes in disease activity over years. Gastroenterology 1994; 107: 3-11.

2. Colombel JF, Rutgeerts P, Reinisch W, et al. Early mucosal healing with infliximab is associated with improved long-term clinical outcomes in ulcerative colitis. Gastroenterology 2011; 141: 1194-201.

3. Frøslie KF, Jahnsen J, Moum BA, Vatn M, IBSEB Group. Mucosal healing in inflammatory bowel disease: results from a Norwegian population-based cohort. Gastroenterology 2007; 133: 412-22.

4. Lichtenstein GR, Rutgeerts P. Importance of mucosal healing in ulcerative colitis. Inflamm Bowel Dis 16: 338-46.

5. Peyrin-Biroulet L, Ferrante M, Magro F, et al. Results from the 2nd scientific workshop of the ECCO. I: Impact of mucosal healing on the course of inflammatory bowel disease. J Crohns Colitis. 2011; 5: 477-83. 
6. Sandborn WJ, Panés J, Zhang H, et al. Correlation between levels of fecal calprotectin and outcomes of patients with ulcerative colitis in a phase 2 trial. Gastroenterology 2016; 150: 96-102.

7. Shah SC, Colombel JF, Sands BE, Narula N. Mucosal healing is associated with improved long-term outcomes of patients with ulcerative colitis: a systematic review and meta-analysis. Clin Gastroenterol Hepatol. 2016; 14: 1245-55.

8. Colombel JF, D'Hasens G, Lee WJ, et al. Outcomes and strategies to support a treat-to-target approach in inflammatory bowel disease: A systematic review. J Crohns Colitis 2020; 14: 254-66.

9. Azab B, Kedia S, Shah N, et al. The value of the pretreatment albumin/globulin ratio in predicting the long-term survival in colorectal cancer. Int J Colorectal Dis 2013; 28: 1629-36.

10. Duran $\mathrm{AO}$, Inanc $\mathrm{M}$, Karaca $\mathrm{H}$, et al. Albumin-globulin ratio for prediction of long-term mortality in lung adenocarcinoma patients. Asian Pac J Cancer Prev. 2014; 15: 6449-53.

11. Azab BN, Bhatt VR, Vonfrolio S, et al. Value of the pretreatment albumin to globulin ratio in predicting long-term mortality in breast cancer patients. Am J Surg 2013; 206: 764-70.

12. Gabay C, Kushner I. Acute-phase proteins and other systemic responses to inflammation. N Engl J Med 1999; 340: 448-54.

13. McMillan DC, Watson WS, O'Gorman P, et al. Albumin concentrations are primarily determined by the body cell mass and the systemic inflammatory response in cancer patients with weight loss. Nutr Cancer 2001; 39: 210-3.

14. Heikkilä K, Ebrahim S, Lawlor DA. A systematic review of the association between circulating concentrations of $C$ reactive protein and cancer. J Epidemiol Community Health 2007; 2061: 824-33.

15. Coussens LM, Werb Z. Inflammation and cancer. Nature 2002; 420: 860-7.

16. Niedziela JT, Hudzik B, Szygula-Jurkiewicz B, et al. Albumin-to-globulin ratio as an independent predictor of mortality in chronic heart failure. Biomark Med 2018; 12: 749-57.

17. Beamer N,Coull BM, Sexton G, Knox R, Seaman G. Fibrinogen and the albuminglobulin ratio in recurrent Stroke 1993; 24: 1133-9.

18. Nandedkar AK,Royal GC Jr, Nandedkar MA. Evaluation of albumin globulin ratio to confirm the clinical stages of sarcoidosis. J Natl Med Assoc 1986; 78: 969-71.

19. Lee SH, Kim MJ, Chang K, et al. Fecal calprotectin predicts complete mucosal healing and better correlates with the ulcerative colitis endoscopic index of severity than with the Mayo endoscopic subscore in patients with ulcerative colitis. BMC Gastroenterol 2017; 27: 110.

20. Seaton K. Albumin concentration controls cancer. J Natl Med Assoc. 2001; 93: 490-3.

21. Kaysen GA. The microinflammatory state in uremia: causes and potential consequences. J Am Soc Nephrol. 2001; 12: 1549-57.

22. Fearon KC, Falconer JS, Slater C, McMillan DC, Preston T. Albumin synthesis rates are not decreased in hypoalbuminemic cachectic cancer patients with an ongoing acute-phase protein response. Ann Surg. 1998; 227: 249-54. 
23. Laky B, Janda M, Bauer J, et al. Malnutrition among gynaecological cancer patients. Eur $\mathrm{J}$ Clin Nutr.2007; 61: 642-6.

24. Du XJ, Tang LL, Mao YP, et al. The pretreatment albumin to globulin ratio has predictive value for long-term mortality in nasopharyngeal carcinoma. PLoS One 2014; 9: e94473.

25. Kimura N, Nakayama Y, Tashiro H. The $15 y$ ear follow-up population survey on cerebrovascular disease in rural Kyushu, Japan. Jpn J Med. 1977; 16: 142-4.

26. Vermeire S, Van Assche G, Rutgeerts P. Laboratory markers in IBD: useful, magic, or unnecessary toys? Gut 2006; 55: 426-31.

27. Solem CA, Loftus EV Jr, Tremaine WJ, et al. Correlation of C-reactive protein with clinical, endoscopic, histologic, and radiographic activity in inflammatory bowel disease. Inflamm Bowel Dis 2005; 11: 707-12.

28. Azzolini F, Pagnini C, Camellini L, et al. Proposal of a new clinical index predictive of endoscopic severity in ulcerative colitis. Dig Dis Sci 2005; 50: 246-51.

29. Oe Y, Mochizuki K, Miyauchi R, et al. Plasma TNF- $a$ is associated with inflammation and nutrition status in community-dwelling Japanese elderly. J Nutr Sci Vitaminol 2015; 61: 263-9.

30. O'Connell TX, Horita TJ, Kasravi B. Understanding and interpreting serum protein electrophoresis. Am Fam Physician. 2005; 71: 105-12.

31. Matsuoka K, Igarashi A, Sato N, et al. Trends in corticosteroid prescriptions for ulcerative colitis and factors associated with longterm corticosteroid use: analysis using Japanese claims data from 2006 to 2016. J Crohns Colitis 2020 (in Press).

\section{Figures}


Figure 1

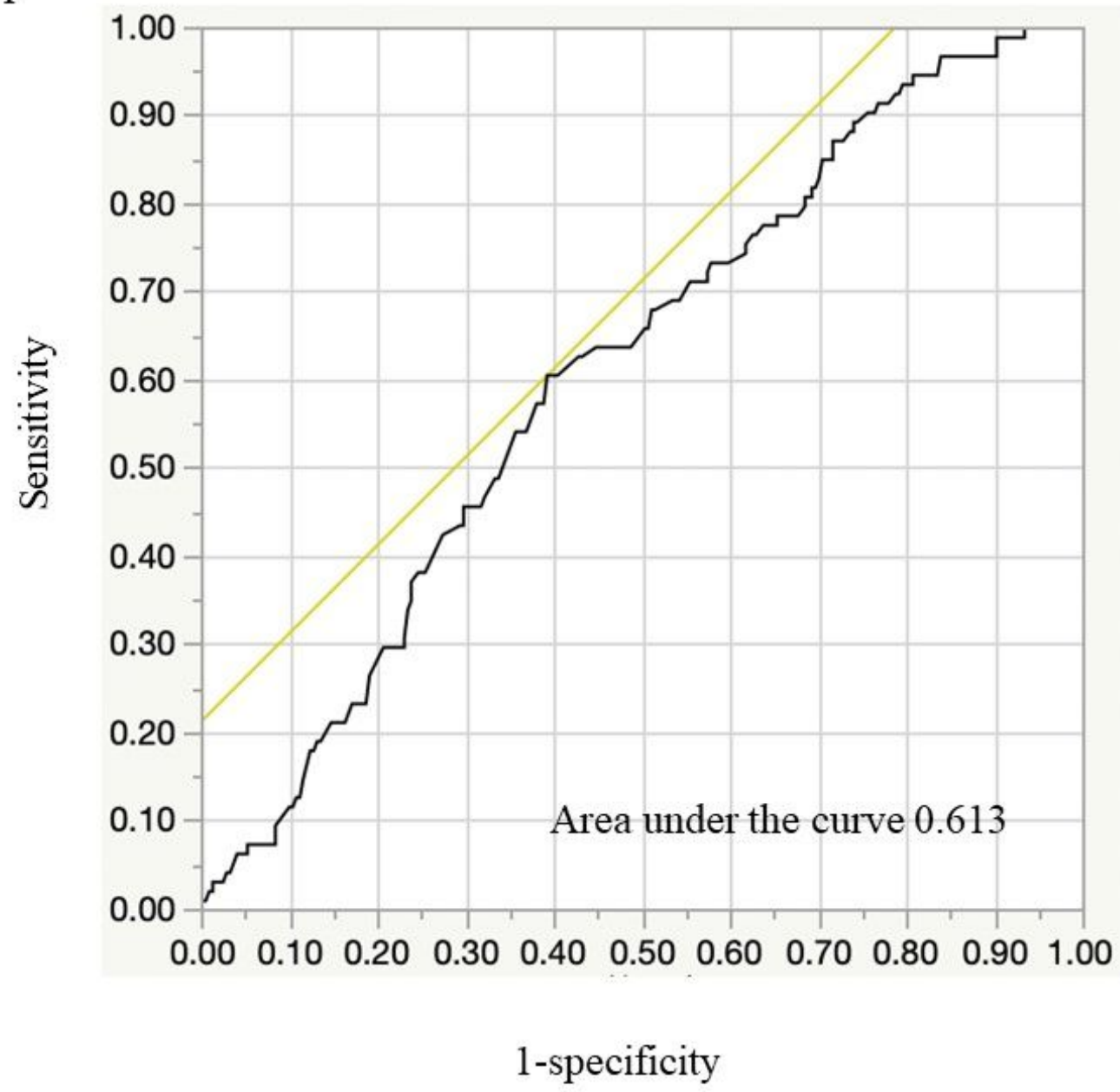

Figure 1

Receiver operating characteristic curve of AGR for identifying the mucosal healing based on Mayo endoscopic subscore 0 . The receiver operating characteristic (ROC) curve AGR for identifying the mucosal healing had an area under curve of 0.613 . When cut off value of AGR was determined as 1.52, the sensitivity and specificity were $60.6 \%$ and $62.1 \%$, respectively. We used Youden Index to calculate the cut off value of AGR 